\title{
Apoptotic genes as potential markers of metastatic phenotype in human osteosarcoma cell lines
}

\author{
CINZIA ZUCCHINI ${ }^{1}$, ANNA ROCCHI ${ }^{2}$, MARIA CRISTINA MANARA ${ }^{2}$, \\ PAOLA DE SANCTIS ${ }^{1}$, CRISTINA CAPANNI ${ }^{3}$, MICHELE BIANCHINI ${ }^{1}$, \\ PAOLO CARINCI $^{1}$, KATIA SCOTLANDI $^{2}$ and LUISA VALVASSORI ${ }^{1}$ \\ ${ }^{1}$ Dipartimento di Istologia, Embriologia e Biologia Applicata, Università di Bologna, Via Belmeloro 8, \\ 40126 Bologna; ${ }^{2}$ Laboratorio di Ricerca Oncologica, Istituti Ortopedici Rizzoli; ${ }^{3}$ IGM-CNR, \\ Unit of Bologna, c/o Istituti Ortopedici Rizzoli, Via di Barbiano 1/10, 40136 Bologna, Italy
}

Received May 29, 2007; Accepted July 19, 2007

\begin{abstract}
Metastasis is the most frequent cause of death among patients with osteosarcoma. We have previously demonstrated in independent experiments that the forced expression of L/B/K ALP and CD99 in U-2 OS osteosarcoma cell lines markedly reduces the metastatic ability of these cancer cells. This behavior makes these cell lines a useful model to assess the intersection of multiple and independent gene expression signatures concerning the biological problem of dissemination. With the aim to characterize a common transcriptional profile reflecting the essential features of metastatic behavior, we employed cDNA microarrays to compare the gene expression profiles of L/B/K ALP- and CD99-transfected osteosarcoma clones showing low metastatic ability with those of osteosarcoma cell lines showing contrasting behavior. Changes in gene expression were validated by real-time PCR and immunohistochemistry in independent samples. In our study we identified several differentially expressed genes (GADD45 $\alpha$, VCP, DHX9, survivin, $\alpha$-catulin, ARPC1B) related to growth arrest and apoptosis. Most of these genes are functionally related with the nuclear factor (NF)- $\mathrm{KB}$ cell survival pathway that appeared to be inhibited in the less malignant osteosarcoma cells. Hence, we propose the inhibition of the NF- $\mathrm{KB}$ pathway as a rational strategy for effective management of human osteosarcoma.
\end{abstract}

\section{Introduction}

Metastasis is the dissemination of cancer cells from the primary tumor to a distant organ and represents the most frequent cause of death for patients with cancer (1). Osteosarcoma (OS) is a

Correspondence to: Dr Katia Scotlandi, Laboratorio di Ricerca Oncologica, Istituti Ortopedici Rizzoli, Via di Barbiano 1/10, 40136 Bologna, Italy

E-mail: katia.scotlandi@ior.it

Key words: gene expression profile, microarray, U2-OS, metastases, nuclear factor- $\mathrm{\kappa B}$ malignant primitive bone tumor, usually developing in children and adolescents, with a high tendency to metastasize (2). Metastases in osteosarcoma patients spread through peripheral blood very early and colonize primarily the lung, and later other skeleton districts (3). Since disseminated hidden micrometastases are present in $80-90 \%$ of OS patients at the time of diagnosis, the identification of markers of invasiveness and metastasis forms a target of paramount importance in planning the treatment of osteosarcoma lesions and enhancing the prognosis.

In this study we performed a statistical analysis of multiple gene expression datasets concerning the common biological problem of metastasis. Our comprehensive analysis includes the gene expression datasets derived from two experimental models previously obtained from the U-2 OS osteosarcoma cell lines characterized by a common reversal of malignancy and lack of metastatic phenotype. In particular, we have demonstrated in independent experiments that the forced expression of L/B/K ALP and likewise CD99 in U-2 OS osteosarcoma cell lines markedly reduces the invasiveness and metastatic ability of these cancer cells $(4,5)$. Alkaline phosphatases (ALPs) are a family of cell surface glycoproteins that catalyze the hydrolysis of phospho-monoesters and release inorganic phosphate. Liver-bone-kidney ( $\mathrm{L} / \mathrm{B} / \mathrm{K}) \mathrm{ALP}$, one of the four major isoenzymes belonging to this family, participates in bone mineralization. The precise biochemical function of bone ALP activity is still unknown, but in U-2 OS osteosarcoma cell lines transfected with the full-length L/B/K ALP gene a reduction in tumorigenic and metastatic ability has been observed associated with high levels of cellular activity of L/B/K ALP (4). CD99 is a transmembrane glycoprotein (6) encoded by the MIC2 gene (7), which has been implicated in several cellular processes, such as cell adhesion, apoptosis and differentiation (8-12). Manara et al (5) have demonstrated that the forced expression of CD99 in two osteosarcoma cell lines significantly inhibits growth in anchorage independence as well as cell migration and leads to abrogation of tumorigenic and metastatic ability.

The fact that U-2 OS osteosarcoma cell lines transfected with both L/B/K ALP and CD99 show identical behavior (that is, marked reduction of metastatic ability), makes these 
Table I. In vitro and in vivo biological features associated with malignancy of U-2 OS transfected clones.

\begin{tabular}{|c|c|c|c|c|}
\hline \multirow[t]{2}{*}{ Cell line } & \multicolumn{2}{|c|}{ In vitro parameters ${ }^{\mathrm{a}}$} & \multicolumn{2}{|c|}{ In vivo behaviour ${ }^{\mathrm{b}}$} \\
\hline & Soft-agar growth & Migration & Mice with tumor/total & Mice with metastases/total \\
\hline U-2 OS & $742 \pm 102$ & $215 \pm 40$ & $7 / 10(70 \%)$ & $16 / 19(84 \%)$ \\
\hline U-2/Empty & $574 \pm 68$ & $218 \pm 40$ & $3 / 5(60 \%)$ & $9 / 10(90 \%)$ \\
\hline U-2/ALP23 & $723 \pm 16$ & $183 \pm 20$ & $3 / 5(60 \%)$ & $10 / 10(100 \%)$ \\
\hline U-2/ALP28 & $109 \pm 7^{\mathrm{c}}$ & $26 \pm 5^{c}$ & $0 / 5(0 \%)$ & $3 / 7(43 \%)$ \\
\hline U-2/ALP40 & $118 \pm 17^{c}$ & $92 \pm 6^{c}$ & $0 / 5(0 \%)$ & $4 / 14(29 \%)$ \\
\hline U-2/CD99wt57 & $67 \pm 17^{c}$ & $90 \pm 18^{c}$ & $0 / 5(0 \%)$ & $0 / 10(0 \%)$ \\
\hline U-2/CD99wt 136 & $124 \pm 26^{c}$ & $64 \pm 17^{c}$ & $0 / 5(0 \%)$ & $7 / 15(47 \%)$ \\
\hline
\end{tabular}

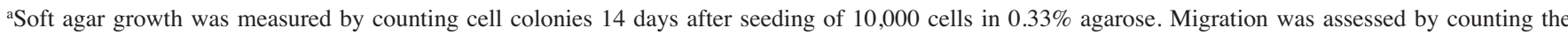
number of cells that migrated towards the filter to reach the lower chamber base of a Trans-well chamber. Cells $\left(10^{5}\right)$ in IMDM plus $1 \%$ FBS were seeded in the upper compartment, whereas IMDM plus $10 \%$ FBS was placed in the lower compartment of the chamber as a chemoattractant. ${ }^{\text {b Tumorigenicity was }}$ determined after subcutaneous injection of $30 \times 10^{6}$ cells in female 4-5 week old Cr1:nu/nu (CD-1)BR athymic mice (Charles River Italia, Como). Experimental metastatic ability was evaluated after injection of $2 \times 10^{6}$ cells into a tail lateral vein. For detailed methods see Manara et al $(4,5)$. $\mathrm{P}<0.05$, Student's t-test.

cell lines a useful model to assess the intersection of multiple and independent gene expression signatures concerning the common biological problem of dissemination. In particular, in our study we employed cDNA microarray technology to compare the gene expression profiles of L/B/K ALP- and CD99-transfected osteosarcoma clones showing low metastatic ability with those of osteosarcoma cell lines showing contrasting behavior, the purpose being to characterize a common transcriptional profile reflecting the essential features of metastatic behavior.

\section{Materials and methods}

Cell lines. The parental osteosarcoma cell line U-2 OS was obtained from the American Type Culture Collection (Manassas, VA). Cells overexpressing L/B/K ALP or CD99 were obtained by using the calcium-phosphate transfection method previously characterized $(4,5)$. Transfectants were selected in $500 \mu \mathrm{g} / \mathrm{ml}$ neomycin (Sigma-Aldrich, St. Louis, MO) and maintained in a selective medium for a maximum of eight in vitro passages before in vitro and in vivo characterization. In particular, U-2/ALP28, and U-2/ALP40, showing high levels of L/B/K ALP expression and activity, and U-2/CD99 clones (U2-CD99wt57 and U2-CD99wt136), overexpressing CD99 at the cell surface, were chosen for their low level of malignancy. Table I summarizes the previously published $(4,5)$ U-2 OS transfectant features associated with cancer malignancy relevant for this study. Cells transfected with the empty vector pcDNA3 (5) or clone U-2/ALP23, which shows very low levels of L/B/K ALP activity (4), were used as negative controls. Cells were routinely cultured in Iscove's modified Dulbecco's medium (IMDM) (Invitrogen, Paisley, Scotland), supplemented with $100 \mathrm{U} / \mathrm{ml}$ penicillin, $100 \mu \mathrm{g} / \mathrm{ml}$ streptomycin and $10 \%$ inactivated fetal bovine serum (FBS) (Cambrex BioScience Verviers, Verviers, Belgium) and maintained at $37^{\circ} \mathrm{C}$ in a humidified $5 \% \mathrm{CO}_{2}$ atmosphere.

RNA isolation. Total RNA was extracted using the TRIzol extraction kit (Invitrogen Life Technologies, Paisley, UK). The quality of RNA samples was determined by electrophoresis through agarose gels and staining with ethidium bromide; the $18 \mathrm{~S}$ and 28S RNA bands were visualized under UV light. To perform microarray hybridization, two independent extractions of RNAs were performed from each cell clone.

cDNA microarray hybridization. Hybridizations were performed on Human 1 cDNA Microarray slides (Agilent Technologies, Inc., Palo Alto, CA) containing 16,281 cDNA sequences. Total RNA was used to obtain labeled cDNA, according to the manufacturer's instructions (Agilent DirectLabel cDNA synthesis kit protocol, Agilent Technologies). cDNA from osteosarcoma cell lines transfected with $\mathrm{L} / \mathrm{B} / \mathrm{K}$ ALP and with CD99 was labeled with Cyanine 5-dCTP (Cy5), while parental U-2/OS cDNA was labeled with Cyanine 3-dCTP (Cy3). In brief, $20 \mu \mathrm{g}$ of total RNA was reversetranscribed with a specific primer mixture using Moloney murine leukemia virus reverse transcriptase (Agilent DirectLabel cDNA synthesis kit) in the presence of $\mathrm{Cy} 5$ or $\mathrm{Cy} 3$ (Perkin-Elmer Life Sciences Inc., Boston, MA) at $42^{\circ} \mathrm{C}$ for $1 \mathrm{~h}$. RNaseI A (Agilent Technologies) was then added to degrade the RNA. Labeled cDNAs were purified with the QIAquick PCR purification kit (Qiagen, GmbH, Germany). Additional washes with $35 \%(\mathrm{w} / \mathrm{v})$ guanidine hydrocloride were performed to ensure efficient removal of the unincorporated dye labeled nucleotides. Equivalent amounts of Cy5- and Cy3-cDNA were combined, vacuum dried, re-suspended in deposition hybridization buffer (Agilent Technologies) with human Cot-1 (Invitrogen) and deposition control targets (Qiagen) and hybridized to microarray slides for approximately $17 \mathrm{~h}$, according to the manufacturer's instructions. The slides were washed with $0.5 \mathrm{X} \mathrm{SSC}+0.01 \% \mathrm{SDS}$ for $10 \mathrm{~min}$ and with $0.06 \mathrm{X} \mathrm{SSC}$ for $5 \mathrm{~min}$.

Microarray analysis. Hybridized slides were scanned using the GenePix 4000A scanner (Axon Instruments, Foster City, CA) ensuring that the total number of saturated spots (saturation fluorescence value: 65,000$)$ was $<10$. Images were analyzed using GENEPIX PRO 3.0 software (Axon Instruments). 
GenePix Post-Processing Script (GP3) was used in order to filter and normalize raw microarray data from GenePix image analysis (13) (global normalization; percentile of mean signal across array for normalization factor: 90 ; threshold value: median background spot intensity +3 standand deviation of background). Expression tables were assembled from GP3 output files and genes that proved to be filtered and preserved in $100 \%$ of the arrays were analyzed using the Significance Analysis of Microarray (SAM) program (14). SAM identifies genes with statistically significant changes in expression by performing a set of gene-specific t-tests. Each gene has a score (d) assigned on the basis of its change in gene expression relative to the standard deviation of repeated measurements for that gene. Only genes showing a score of $>2.5$ or $<-2.5$ were considered, and among these, only genes up-regulated or down-regulated in at least $85 \%$ of the arrays were selected and employed for functional analysis.

Gene ontology (GO). We used FatiGO to assign the 253 differently expressed genes to non-mutually exclusive categories regarding biological processes. FatiGO is a web interface (http://fatigo.bioinfo.cipf.es) which carries out simple data mining using GO for DNA microarray data. The data mining consists in assigning the most characteristic GO term to each cluster. When we searched for the distribution of genes in a specific ontology (e.g. a biological process) we selected the ontology and also the GO term level (=3).

Real-time PCR. Total RNA $(1 \mu \mathrm{g})$ was denatured at $65^{\circ} \mathrm{C}$ for $10 \mathrm{~min}$ and then reverse-transcribed in a $100-\mu 1$ reaction mixture containing $500 \mu \mathrm{M}$ of each dNTP, $125 \mathrm{U}$ of MultiScribe reverse transcriptase (Applied Biosystems, Foster City, CA), $40 \mathrm{U}$ of RNase inhibitor (Applied Biosystems), $2.5 \mu \mathrm{M}$ oligo d(T), $1 \mathrm{X}$ TaqMan RT Buffer, and $5 \mathrm{mM} \mathrm{MgCl}_{2}$ at $48^{\circ} \mathrm{C}$ for $40 \mathrm{~min}$. Reactions performed in the absence of enzyme or RNA were used as negative controls. Gene-specific primers were designed using Primer Express software (Applied Biosystems): Glyceraldehyde-3-phosphate dehydrogenase (GAPDH) primers and probe as follows: forward 5' GAAGG TGAAGGTCGGAGTC 3', reverse 5' GAAGATGGTGATG GGATTTC 3'; probe: FAM-GAA 5' GCTTCCCGTTCTCA GCC 3'. Actin Related Protein 2/3 Complex, Subunit 1B, $41 \mathrm{kDa}$ (ARPC1B): forward 5' TCAAGTGTCGGATCTTT TCAGC 3', reverse 5' AGTTCCCCAAAGGGCATCTT 3'. $\alpha$-catulin [Catenin (cadherin-associated protein), $\alpha$-like 1 , CTNNAL1]: forward 5' AGTGGGGAAGATGCAGTCC 3', reverse 5' CAAATGACAGCTAAACAGCAGC 3'. Survivin (Baculoviral IAP Repeat-Containing 5, BIRC5): forward 5' TGGCCCAGTGTTTCTTCTGC 3', reverse 5' CAACCGGA CGAATGCTTTTT 3'. Valosin-containing protein (VCP): forward 5' GTAACCTGGGAAGACATCGGG 3', reverse 5' GGAATTTGTCTGGGTGCTCC 3'. A SYBR-Green PCR Master mix (Applied Biosystems) was used with $1 \mathrm{ng}$ of cDNA and with 100-400 nM of the primers. A negative control without any cDNA template was run with every assay. All PCR reactions were performed using an ABI PRISM 7900 sequence detection system (PE Applied Biosystems). The target gene mRNA was quantified by measuring the $\mathrm{C}_{\mathrm{T}}$ (threshold cycle) to determine the relative expression. Data were normalized to GAPDH. The relative expression of the different mRNAs was also normalized to U-2 OS mRNA, used as a calibrator and was expressed as: $2^{-\Delta \Lambda C T}$, where $\Delta \mathrm{C}_{\mathrm{T}}=\mathrm{C}_{\mathrm{T}}$ target genes $\mathrm{C}_{\mathrm{T}} \mathrm{GAPDH}$, and $\Delta \Delta \mathrm{CT}=\Delta \mathrm{C}_{\mathrm{T}}$ sample $-\Delta \mathrm{C}_{\mathrm{T}}$ calibrator. All samples were resolved in a $2 \%$ agarose gel to confirm the PCR specificity.

Analysis of apoptosis. Detection and quantification of apoptotic cells was obtained by flow cytometric analysis (FACSCalibur, Becton Dickinson) of annexin-V-FITC-labelled cells. This test was performed according to the manufacturer's instructions (Medical and Biological Laboratories, Naka-ku Nagaya, Japan). PI incorporation was evaluated in combination with the fluorescent signal intensity to allow for discrimination of necrotic and apoptotic cells.

Poly-HEMA assay. Six-well plates were treated with poly-2 hydroxyethylmethacrylate (poly-HEMA) (Sigma) following the method of Folkman and Moscona (15). Briefly, wells were treated with a 1-ml solution of poly-HEMA diluted in $95 \%$ ethanol $(12 \mathrm{mg} / \mathrm{ml})$ and left to dry at room temperature. Cells $(250,000 /$ well $)$ were seeded in IMDM $10 \%$ FBS and incubated at $37^{\circ} \mathrm{C}$ in a humidified $5 \% \mathrm{CO}_{2}$ atmosphere. Viable and dead cells were counted after 24, 48, and $72 \mathrm{~h}$. Detection and quantification of apoptotic cells as well as of cell cycle phases was obtained according to the procedures described above.

Immunostainings on adherent fixed cells. Cells were seeded in IMDM 10\% FBS and grown on coverslips for $48 \mathrm{~h}$ before being fixed in $4 \%$ paraformaldehyde at room temperature and permeabilized with $0.15 \%$ Triton X-100 in PBS. All preparations were incubated with PBS containing $4 \%$ BSA to saturate non-specific binding. Immunofluorescence staining for cyclin D1 and NF- $\mathrm{BB}$ was performed with the primary cyclin D1 (H-295) MAb (Santa Cruz Biotechnolgy, Inc.) (diluted 1:10) or anti NF-кBp50 (H-119) MAb (Santa Cruz Biotechnolgy, Inc.) (diluted 1:20), respectively. FITCconjugated phalloidin (5 U/ml) (Sigma) was applied for $30 \mathrm{~h}$ at room temperature to stain and visualize actin filaments.

Wound-healing assay. Monolayer wounds were made using a pipette tip on confluent cells. Cell migration was visualized, at regular intervals of time, at x100 magnification using an inverted microscope (Nikon Diaphot, Melville, NY), and photographed with a D70s Nikon digital camera (Nikon).

Nuclei extraction and $N F-\kappa B$ Western blotting. The cell pellet was resuspended in a buffer containing $10 \mathrm{mM}$ Tris, $\mathrm{pH} 7.8$, $1 \%$ NP-40, $10 \mathrm{mM}$ 2-mercaptoethanol and protease inhibitors. Separation of nuclei was obtained by hypotonic shock and shearing; nuclei were obtained as pellet by a $300 \mathrm{x}$ g centrifugation at $4{ }^{\circ} \mathrm{C}$. Cytoplasmic fractions were clarified by centrifugation at $600 \mathrm{~g}$. Each fraction was then resuspended in loading buffer, subjected to sodium dodecylsulphate polyacrylamide gel electrophoresis (SDS PAGE) and Western blot analysis. The expression of NF- $\mathrm{BB}$ in the nuclei was evaluated using anti-NF-кBp50 (H-119) MAb (Santa Cruz Biotechnolgy, Inc.) (diluted 1:100). The absence of cytoplasmic contamination in the nuclear fraction was checked by staining the cellular fractions with anti-GAPDH Mab (FL-335) (diluted 1:2000). 
Table II. Up-regulated and down-regulated expressed genes in both L/B/K ALP and CD99 U2-OS transfected clones showing lack of metastatic ability compared with parental U2-OS cell line.

\begin{tabular}{|c|c|c|c|}
\hline Gene symbol & Gene name & Unigene & Score $(d)$ \\
\hline \multicolumn{4}{|c|}{ Up-regulated genes } \\
\hline KIF23 & Kinesin family member 23 & Hs. 270845 & 5.872 \\
\hline CRYAB & Homo sapiens crystallin, $\alpha \mathrm{B}$ & Hs.408767 & 5.718 \\
\hline OXA1L & Oxidase (cytochrome c) assembly 1-like & Hs. 151134 & 3.853 \\
\hline DUSP12 & Dual specificity phosphatase 12 & Hs. 416216 & 3.545 \\
\hline VGF & VGF nerve growth factor inducible & Hs. 439672 & 3.491 \\
\hline GNG11 & Guanine nucleotide binding protein (G protein), $\gamma 11$ & Hs.83381 & 3.401 \\
\hline MTHFD2 & $\begin{array}{l}\text { Methylenetetrahydrofolate dehydrogenase }\left(\mathrm{NADP}^{+} \text {dependent) } 2 \text {, methenyltetrahydrofolate }\right. \\
\text { cyclohydrolase }\end{array}$ & Hs.469030 & 3.385 \\
\hline RAD51C & RAD51 homolog C (S.cerevisiae) & Hs. 412587 & 3.382 \\
\hline BUB1 & Budding uninhibited by benzimidazoles 1 homolog (yeast) & Hs.469649 & 3.38 \\
\hline ANXA1 & Annexin A1 & Hs. 494173 & 3.376 \\
\hline TAF13 & TAF13 RNA polymerase II, TATA box binding protein (TBP)-associated factor, $18 \mathrm{kDa}$ & Hs. 502508 & 3.339 \\
\hline PMAIP1 & Phorbol-12-myristate-13-acetate-induced protein 1 & Hs.96 & 3.32 \\
\hline SLC38A2 & Solute carrier family 38 , member 2 & Hs. 221847 & 3.207 \\
\hline ANAPC10 & Anaphase promoting complex subunit 10 & Hs. 480876 & 3.162 \\
\hline SLC22A11 & Solute carrier family 22 (organic anion/cation transporter), member 11 & Hs. 220844 & 3.139 \\
\hline MTX2 & metaxin 2 & Hs. 470728 & 3.104 \\
\hline SBDS & Shwachman-Bodian-Diamond syndrome & Hs.110445 & 3.08 \\
\hline $\mathrm{RCN} 2$ & Reticulocalbin 2, EF-hand calcium binding domain & Hs.79088 & 3.079 \\
\hline PBK & PDZ binding kinase & Hs.104741 & 3.059 \\
\hline PCDHGC3 & protocadherin $\gamma$ subfamily $\mathrm{C}, 3$ gene, exon 1 & Hs. 368160 & 3.023 \\
\hline TJP2 & Tight junction protein 2 (zona occludens 2 ) & Hs.50382 & 3.006 \\
\hline COPS4 & COP9 constitutive photomorphogenic homolog subunit 4 (Arabidopsis) & Hs.190384 & 2.974 \\
\hline CTGF & Connective tissue growth factor & Hs. 410037 & 2.93 \\
\hline TRO & Trophinin & Hs.434971 & 2.899 \\
\hline SNAPC1 & Small nuclear RNA activating complex, polypeptide $1,43 \mathrm{kDa}$ & Hs.179312 & 2.89 \\
\hline TPT1 & Tumor protein, translationally-controlled 1 & Hs. 374596 & 2.887 \\
\hline RPL9 & Ribosomal protein L9 & Hs. 513083 & 2.883 \\
\hline NAT5 & $\mathrm{N}$-acetyltransferase 5 (ARD1 homolog, S. cerevisiae) & Hs.368783 & 2.852 \\
\hline EIF3S6 & Eukaryotic translation initiation factor 3, subunit $648 \mathrm{kDa}$ & Hs.405590 & 2.848 \\
\hline ADAM9 & A disintegrin and metalloproteinase domain 9 (meltrin $\gamma$ ) & Hs.591852 & 2.821 \\
\hline DDEF1 & Development and differentiation enhancing factor 1 & Hs. 106015 & 2.794 \\
\hline RTN4 & Reticulon 4 & Hs.645283 & 2.785 \\
\hline COX6C & Cytochrome $\mathrm{c}$ oxidase subunit VIc & Hs. 351875 & 2.778 \\
\hline PGRMC1 & Progesterone receptor membrane component 1 & Hs.90061 & 2.776 \\
\hline GAD2 & Glutamate decarboxylase 2 (pancreatic islets and brain, $65 \mathrm{kDa}$ ) & Hs.231829 & 2.768 \\
\hline \multirow[t]{2}{*}{ TBCA } & Tubulin-specific chaperone a & Hs.495912 & 2.766 \\
\hline & Transcribed locus & Hs. 598710 & 2.742 \\
\hline WSB2 & WD repeat and SOCS box-containing 2 & Hs. 506985 & 2.726 \\
\hline PRNP & $\begin{array}{l}\text { prion protein (p27-30) (Creutzfeldt-Jakob disease, Gerstmann-Strausler-Scheinker syndrome, fatal } \\
\text { familial insomnia) }\end{array}$ & Hs. 472010 & 2.706 \\
\hline DDX18 & DEAD (Asp-Glu-Ala-Asp) box polypeptide 18 & Hs.363492 & 2.702 \\
\hline PHLDA2 & Pleckstrin homology-like domain, family A, member 2 & Hs. 154036 & 2.702 \\
\hline TM4SF8 & Tetraspanin 3 & Hs. 5062 & 2.681 \\
\hline HSBP1 & Heat shock factor binding protein 1 & Hs.250899 & 2.673 \\
\hline SDHD & Succinate dehydrogenase complex, subunit $\mathrm{D}$, integral membrane protein & Hs. 356270 & 2.663 \\
\hline RPS15A & Ribosomal protein S15a & Hs. 370504 & 2.66 \\
\hline NDUFB3 & NADH dehydrogenase (ubiquinone) $1 ß$ subcomplex, $3,12 \mathrm{kDa}$ & Hs. 109760 & 2.649 \\
\hline
\end{tabular}


Table II. Continued.

\begin{tabular}{|c|c|c|c|}
\hline Gene symbol & Gene name & Unigene & Score (d) \\
\hline PHF20 & PHD finger protein 20 & Hs.517044 & 2.636 \\
\hline RPA3 & Replication protein $\mathrm{A} 3,14 \mathrm{kDa}$ & Hs. 487540 & 2.634 \\
\hline PPP1R8 & Protein phosphatase 1 , regulatory (inhibitor) subunit 8 & Hs. 533474 & 2.634 \\
\hline AP3B1 & Adaptor-related protein complex $3, \beta 1$ subunit & Hs.532091 & 2.632 \\
\hline SF3B1 & Splicing factor $3 \mathrm{~b}$, subunit $1,155 \mathrm{kDa}$ & Hs.632554 & 2.626 \\
\hline DNAJC3 & DnaJ (Hsp40) homolog, subfamily C, member 3 & Hs.591209 & 2.623 \\
\hline UAP1 & UDP-N-acteylglucosamine pyrophosphorylase 1 & Hs.492859 & 2.62 \\
\hline GADD45A & growth arrest and DNA-damage-inducible, $\alpha$ & Hs.80409 & 2.613 \\
\hline ITM2B & Integral membrane protein $2 \mathrm{~B}$ & Hs.652143 & 2.61 \\
\hline RPS24 & Ribosomal protein $\mathrm{S} 24$ & Hs.356794 & 2.61 \\
\hline RPL7 & Ribosomal protein L7 & Hs. 571841 & 2.605 \\
\hline PTPN2 & Protein tyrosine phosphatase, non-receptor type 2 & Hs. 123352 & 2.594 \\
\hline SSR1 & Signal sequence receptor, $\alpha$ (translocon-associated protein $\alpha$ ) & Hs. 114033 & 2.594 \\
\hline COX7B & Cytochrome c oxidase subunit VIIb & Hs.522699 & 2.59 \\
\hline CPOX & Coproporphyrinogen oxidase & Hs.476982 & 2.589 \\
\hline PPP2CB & protein phosphatase 2 (formerly $2 \mathrm{~A}$ ), catalytic subunit, $B$ isoform & Hs. 491440 & 2.588 \\
\hline KIF5B & Kinesin family member $5 B$ & Hs.591373 & 2.584 \\
\hline NDUFAB1 & NADH dehydrogenase (ubiquinone) $1, \alpha / \beta$ subcomplex, $1,8 \mathrm{kDa}$ & Hs.189716 & 2.575 \\
\hline STRAP & Serine/threonine kinase receptor associated protein & Hs. 504895 & 2.572 \\
\hline NUP107 & Nucleoporin 107 kDa & Hs. 524574 & 2.564 \\
\hline DHFR & Dihydrofolate reductase & Hs.83765 & 2.56 \\
\hline MAD2L1 & MAD2 mitotic arrest deficient-like 1 (yeast) & Hs.591697 & 2.54 \\
\hline ACTL6A & Actin-like 6A & Hs.432356 & 2.539 \\
\hline HAT1 & Histone acetyltransferase 1 & Hs.632532 & 2.537 \\
\hline ITGA6 & Integrin, $\alpha 6$ & Hs.133397 & 2.531 \\
\hline SNRPG & Small nuclear ribonucleoprotein polypeptide $\mathrm{G}$ & Hs. 516076 & 2.526 \\
\hline ZNF502 & zinc finger protein 502 & Hs.224843 & 2.522 \\
\hline TIAL1 & TIA1 cytotoxic granule-associated RNA binding protein-like 1 & Hs.501203 & 2.521 \\
\hline CTNNAL1 & Catenin (cadherin-associated protein), $\alpha$-like 1 & Hs.58488 & 2.516 \\
\hline \multicolumn{4}{|c|}{ Down-regulated genes } \\
\hline NOLC1 & Nucleolar and Coiled-Body Phosphoprotein 1 & Hs.523238 & -6.736 \\
\hline TPM2 & Tropomyosin $2(ß)$ & Hs.300772 & -6.692 \\
\hline EEF1D & Eukaryotic Translation Elongation Factor $1 \delta$ (Guanine Nucleotide Exchange Protein) & Hs.333388 & -5.508 \\
\hline TPM3 & Tropomyosin 3 & Hs.129512 & -5.457 \\
\hline THOC4 & THO Complex 4 & Hs. 534385 & -5.237 \\
\hline HSPCB & Heat Shock 90 kDa Protein 1, $\beta$ & Hs.509736 & -5.066 \\
\hline HNRPA2B1 & Heterogeneous Nuclear Ribonucleoprotein A2/B1 & Hs.487774 & -5.018 \\
\hline LIG1 & Ligase I, DNA, ATP-Dependent & Hs.1770 & -4.922 \\
\hline NDUFV1 & NADH Dehydrogenase (Ubiquinone) Flavoprotein 1, $51 \mathrm{kDa}$ & Hs.7744 & -4.908 \\
\hline TUBA1 & Tubulin, $\alpha 1$ (Testis Specific) & Hs.75318 & -4.838 \\
\hline ECHS1 & Enoyl Coenzyme A Hydratase, Short Chain, 1, Mitochondrial & Hs.76394 & -4.823 \\
\hline HADHA & $\begin{array}{l}\text { Hydroxyacyl-Coenzyme A Dehydrogenase/3-Ketoacyl-Coenzyme A Thiolase/Enoyl-Coenzyme A } \\
\text { Hydratase (Trifunctional Protein), } \alpha \text { subunit }\end{array}$ & Hs. 516032 & -4.748 \\
\hline LMAN2 & Lectin, Mannose-Binding 2 & Hs.75864 & -4.721 \\
\hline TTN & Titin & Hs. 134602 & -4.698 \\
\hline GANAB & Glucosidase, $\alpha$; Neutral AB & Hs.595071 & -4.589 \\
\hline TUBB4Q & Tubulin, ß Polypeptide 4, Member Q & Hs.351544 & -4.58 \\
\hline TSR2 & TSR2, 20S rRNA Accumulation, Homolog (S. Cerevisiae) & Hs.522662 & -4.502 \\
\hline PTMA & Prothymosin, $\alpha$ (gene sequence 28 ) & Hs.459927 & -4.489 \\
\hline DHX9 & DEAH (Asp-Glu-Ala-His) box polypeptide 9 & Hs. 191518 & -4.485 \\
\hline
\end{tabular}


Table II. Continued.

\begin{tabular}{|c|c|c|c|}
\hline Gene symbol & Gene name & Unigene & Score $(d)$ \\
\hline SMARCA4 & SWI/SNF related, matrix associated, actin dependent regulator of chromatin, subfamily a, member 4 & Hs.327527 & -4.473 \\
\hline TUBAL3 & Tubulin, $\alpha$-like 3 & Hs.163079 & -4.436 \\
\hline $\mathrm{VCP}$ & Valosin-Containing Protein & Hs.529782 & -4.412 \\
\hline SYNGR2 & Synaptogyrin 2 & Hs.464210 & -4.251 \\
\hline SFN & Stratifin & Hs.523718 & -4.25 \\
\hline EIF4H & Eukaryotic Translation Initiation Factor $4 \mathrm{H}$ & Hs.520943 & -4.217 \\
\hline PCOLN3 & Procollagen (Type III) N-Endopeptidase & Hs.589427 & -4.216 \\
\hline ETFB & Electron-transfer-flavoprotein, $\beta$ polypeptide & Hs.74047 & -4.097 \\
\hline HLA-E & Major Histocompatibility Complex, Class I, E & Hs.118354 & -4.089 \\
\hline STK24 & Serine/threonine kinase 24 (STE20 homolog, yeast) & Hs. 508514 & -4.076 \\
\hline SF3B2 & Splicing factor $3 \mathrm{~b}$, subunit $2,145 \mathrm{kDa}$ & Hs.406423 & -4.022 \\
\hline SRF & Serum Response Factor (C-Fos Serum Response Element-Binding Transcription Factor) & Hs. 520140 & -4.01 \\
\hline FKBP2 & FK506 binding protein $2,13 \mathrm{kDa}$ & Hs.227729 & -4.009 \\
\hline ENO2 & Enolase $2(\gamma$, neuronal $)$ & Hs.511915 & -3.99 \\
\hline CALR & Calreticulin & Hs.515162 & -3.919 \\
\hline HNRPH3 & Heterogeneous Nuclear Ribonucleoprotein H3 (2H9) & Hs.652156 & -3.909 \\
\hline NCL & Nucleolin & Hs.79110 & -3.908 \\
\hline DKC1 & Dyskeratosis Congenita 1, Dyskerin & Hs. 4747 & -3.891 \\
\hline TUBA1 & Tubulin, $\alpha 1$ & Hs.75318 & -3.889 \\
\hline PIK4CB & Phosphatidylinositol 4-Kinase, Catalytic, ß polypeptide & Hs.632465 & -3.871 \\
\hline CDC37 & CDC37 Cell Division Cycle 37 Homolog (S. Cerevisiae) & Hs.160958 & -3.868 \\
\hline AMFR & Autocrine Motility Factor Receptor & Hs.295137 & -3.867 \\
\hline CHST10 & Carbohydrate Sulfotransferase 10 & Hs.516370 & -3.82 \\
\hline UBE2S & Ubiquitin-Conjugating Enzyme E2S & Hs.396393 & -3.775 \\
\hline DYNC1H1 & Dynein, Cytoplasmic 1, Heavy Chain 1 & Hs.569312 & -3.701 \\
\hline PYCR1 & Pyrroline-5-Carboxylate Reductase 1 & Hs.458332 & -3.69 \\
\hline EML4 & Echinoderm Microtubule Associated Protein Like 4 & Hs.593614 & -3.663 \\
\hline SLC25A6 & Solute Carrier Family 25 (Mitochondrial Carrier; Adenine Nucleotide Translocator), member 6 & Hs.350927 & -3.646 \\
\hline IFRD2 & Interferon-Related Developmental Regulator 2 & Hs. 315177 & -3.63 \\
\hline FEN1 & Flap Structure-Specific Endonuclease 1 & Hs.409065 & -3.629 \\
\hline CDC20 & CDC20 Cell Division Cycle 20 Homolog (S. Cerevisiae) & Hs.524947 & -3.577 \\
\hline GNB2 & Guanine Nucleotide Binding Protein (G Protein), $\beta$ polypeptide 2 & Hs.185172 & -3.564 \\
\hline B4GALT6 & UDP-Gal:ßglcnac ß 1,4- Galactosyltransferase, polypeptide 6 & Hs.591063 & -3.557 \\
\hline PKM2 & Pyruvate Kinase, muscle & Hs. 534770 & -3.551 \\
\hline LRPAP1 & Low Density Lipoprotein Receptor-Related Protein Associated Protein 1 & Hs.533136 & -3.547 \\
\hline TK1 & Thymidine Kinase 1, Soluble & Hs.515122 & -3.537 \\
\hline MCAM & Melanoma Cell Adhesion Molecule & Hs.599039 & -3.532 \\
\hline NDUFB7 & NADH Dehydrogenase (Ubiquinone) 1 ß subcomplex, 7, $18 \mathrm{kDa}$ & Hs.532853 & -3.53 \\
\hline ACTG1 & Actin, $\gamma 1$ & Hs.514581 & -3.53 \\
\hline U2AF1 & U2(RNU2) Small Nuclear RNA Auxiliary Factor 1 & Hs.365116 & -3.502 \\
\hline PEBP1 & Phosphatidylethanolamine Binding Protein 1 & Hs.652392 & -3.5 \\
\hline RBM4 & RNA Binding Motif Protein 4 & Hs.533712 & -3.49 \\
\hline MLC1SA & Myosin, Light Chain 6B, Alkali, smooth muscle and non-muscle & Hs.632731 & -3.481 \\
\hline DHX38 & DEAH (Asp-Glu-Ala-His) Box Polypeptide 38 & Hs.570079 & -3.472 \\
\hline TUBB2B & Tubulin, ß 2B & Hs.300701 & -3.468 \\
\hline ARF1 & ADP-Ribosylation Factor 1 & Hs.286221 & -3.466 \\
\hline TWF2 & Twinfilin, Actin-Binding Protein, Homolog 2 (Drosophila) & Hs.436439 & -3.449 \\
\hline AMY2A & Amylase, $\alpha 2 \mathrm{~A}$; Pancreatic & Hs.484588 & -3.438 \\
\hline ССТ3 & Chaperonin Containing TCP1, Subunit $3(\gamma)$ & Hs.491494 & -3.433 \\
\hline GSR & Glutathione Reductase & Hs. 271510 & -3.421 \\
\hline
\end{tabular}


Table II. Continued.

\begin{tabular}{|c|c|c|c|}
\hline Gene symbol & Gene name & Unigene & Score $(d)$ \\
\hline SIAHBP1 & Fuse-Binding Protein-Interacting Repressor & Hs.521924 & -3.415 \\
\hline ACTA2 & Actin, $\alpha 2$, smooth muscle, aorta & Hs. 500483 & -3.413 \\
\hline SNX17 & Sorting Nexin 17 & Hs. 278569 & -3.399 \\
\hline ACTG2 & Actin, $\gamma 2$, Smooth Muscle, Enteric & Hs. 516105 & -3.397 \\
\hline HSP90AB1 & Heat Shock Protein $90 \mathrm{kDa} \alpha$ (Cytosolic), Class B Member 1 & Hs .649923 & -3.389 \\
\hline ZNF43 & Zinc Finger Protein 43 & Hs .534365 & -3.383 \\
\hline PAM & Peptidylglycine $\alpha$-Amidating Monooxygenase & Hs. 369430 & -3.378 \\
\hline EIF3S9 & Eukaryotic Translation Initiation factor 3 , Subunit $9 \eta, 116 \mathrm{kDa}$ & Hs.371001 & -3.368 \\
\hline TUBA3 & Tubulin, $\alpha 3$ & Hs. 524390 & -3.36 \\
\hline RORA & RAR-Related Orphan Receptor A & Hs.569497 & -3.351 \\
\hline TK1 & Thymidine Kinase 1, Soluble & Hs. 515122 & -3.349 \\
\hline EIF4E2 & Eukaryotic Translation Initiation Factor 4E Member 2 & Hs.292026 & -3.285 \\
\hline NAT10 & N-Acetyltransferase 10 & Hs.577281 & -3.272 \\
\hline PCGF2 & Polycomb Group Ring Finger 2 & Hs. 371617 & -3.259 \\
\hline KIAA0174 & KIAA0174 & Hs.232194 & -3.249 \\
\hline BIRC5 & Baculoviral IAP Repeat-Containing 5 (Survivin) & Hs .645371 & -3.234 \\
\hline SLC35C2 & Solute Carrier Family 35, Member C2 & Hs.593344 & -3.221 \\
\hline EFTUD2 & Elongation Factor TU GTP Binding Domain Containing 2 & Hs.151787 & -3.213 \\
\hline PABPC4 & Poly(A) Binding Protein, Cytoplasmic 4 (Inducible form) & Hs. 169900 & -3.2 \\
\hline CSTF2 & Cleavage Stimulation Factor, 3' Pre-RNA, Subunit 2, 64 kDa & Hs. 132370 & -3.196 \\
\hline TPI1 & Triosephosphate Isomerase 1 & Hs. 524219 & -3.196 \\
\hline ASNA1 & ArsA Arsenite Transporter, ATP-Binding, Homolog 1 (Bacterial) & Hs .465985 & -3.185 \\
\hline GLG1 & Golgi Apparatus Protein 1 & Hs. 201712 & -3.182 \\
\hline MLLT7 & Myeloid/Lymphoid or Mixed-Lineage Leukemia (Trithorax Homolog, Drosophila); translocated to, 7 & Hs. .584654 & -3.166 \\
\hline DDX39 & DEAD (Asp-Glu-Ala-Asp) box polypeptide 39 & Hs.311609 & -3.165 \\
\hline BAK1 & Bcl2-Antagonist/Killer 1 & Hs .485139 & -3.156 \\
\hline VAT1 & Vesicle Amine Transport Protein 1 Homolog (T Californica) & Hs. 514199 & -3.155 \\
\hline EIF3S2 & Eukaryotic Translation Initiation Factor 3, subunit 2 B, $36 \mathrm{kDa}$ & Hs.530096 & -3.147 \\
\hline $\mathrm{P} 4 \mathrm{HB}$ & Procollagen-Proline, 2-Oxoglutarate 4-Dioxygenase (Proline 4-Hydroxylase), ß polypeptide & Hs.464336 & -3.141 \\
\hline LOC729708 & LOC729708: Similar to Triosephosphate Isomerase (TIM) (Triose-Phosphate Isomerase) & Hs.567941 & -3.125 \\
\hline HIST1H3D & Histone Cluster $1, \mathrm{H} 3 \mathrm{~d}$ & Hs. 532144 & -3.12 \\
\hline PSMB6 & Proteasome (Prosome, Macropain) subunit, $\beta$ type, 6 & Hs.77060 & -3.114 \\
\hline EXOC3 & Exocyst Complex Component 3 & Hs.646923 & -3.114 \\
\hline GNL1 & Guanine Nucleotide Binding Protein-Like 1 & Hs .83147 & -3.093 \\
\hline TOMM40 & Translocase of Outer Mitochondrial Membrane 40 Homolog (Yeast) & Hs.110675 & -3.09 \\
\hline MAPKAPK3 & Mitogen-Activated Protein Kinase-Activated Protein Kinase 3 & Hs .234521 & -3.087 \\
\hline RPN1 & Ribophorin I & Hs. 518244 & -3.075 \\
\hline SSRP1 & Structure Specific Recognition Protein 1 & Hs. 523680 & -3.074 \\
\hline PRNPIP & Prion Protein Interacting Protein & Hs.132497 & -3.062 \\
\hline AP2M1 & Adaptor-Related Protein Complex 2, MU 1 Subunit & Hs. 518460 & -3.059 \\
\hline UPP1 & Uridine Phosphorylase 1 & Hs .488240 & -3.059 \\
\hline LY6E & Lymphocyte Antigen 6 Complex, locus E & Hs.521903 & -3.056 \\
\hline ARPC1B & Actin Related Protein 2/3 Complex, Subunit 1B, $41 \mathrm{kDa}$ & Hs. 489284 & -3.051 \\
\hline FARSLA & Phenylalanine-tRNA Synthetase-Like, $\alpha$ Subunit & Hs.23111 & -3.044 \\
\hline POLA2 & Polymerase (DNA directed), $\alpha 2$ (70 kDa Subunit) & Hs .201897 & -3.043 \\
\hline RFC5 & Replication Factor C (Activator 1) 5, $36.5 \mathrm{kDa}$ & Hs.506989 & -3.042 \\
\hline MLF2 & Myeloid Leukemia Factor 2 & Hs.524214 & -3.034 \\
\hline AIP & Aryl Hydrocarbon Receptor Interacting Protein & Hs. 412433 & -3.021 \\
\hline MRPL28 & Mitochondrial Ribosomal Protein L28 & Hs .513230 & -3.015 \\
\hline PPP2R4 & Protein Phosphatase 2A, Regulatory Subunit B' (PR 53) & Hs .400740 & -3.008 \\
\hline
\end{tabular}


Table II. Continued.

\begin{tabular}{|c|c|c|c|}
\hline Gene symbol & Gene name & Unigene & Score $(d)$ \\
\hline KEAP1 & Kelch-Like Ech-Associated Protein 1 & Hs.465870 & -2.985 \\
\hline SNRPN & Small Nuclear Ribonucleoprotein Polypeptide N & Hs. 564847 & -2.965 \\
\hline CLIC1 & Chloride Intracellular Channel 1 & Hs. 414565 & -2.965 \\
\hline HNRPU & Heterogeneous Nuclear Ribonucleoprotein U (Scaffold Attachment Factor A) & Hs. 166463 & -2.958 \\
\hline FTL & Ferritin, Light Polypeptide & Hs.433670 & -2.957 \\
\hline NDUFS2 & NADH Dehydrogenase (Ubiquinone) Fe-S Protein 2, 49 kDa (NADH-Coenzyme Q Reductase) & Hs.173611 & -2.946 \\
\hline RBP1 & Retinol binding protein 1 , cellular & Hs.529571 & -2.944 \\
\hline KRT17 & Keratin 17 & Hs .2785 & -2.932 \\
\hline PPP1CA & Protein Phosphatase 1, Catalytic Subunit, $\alpha$ isoform & Hs.183994 & -2.931 \\
\hline HEXA & Hexosaminidase A ( $\alpha$ polypeptide) & Hs.604479 & -2.924 \\
\hline HSPA8 & Heat Shock $70 \mathrm{kDa}$ Protein 8 & Hs.180414 & -2.917 \\
\hline TRAP1 & TNF Receptor-Associated Protein 1 & Hs.30345 & -2.904 \\
\hline ATP6V0D1 & ATPase, $\mathrm{H}^{+}$Transporting, Lysosomal 38 kDa, V0 Subunit D1 & Hs. 106876 & -2.901 \\
\hline TNIP1 & TNFAIP3 Interacting Protein 1 & Hs. 543850 & -2.901 \\
\hline MARCKSL1 & Marcks-Like 1 & Hs.75061 & -2.892 \\
\hline BCAP31 & B-cell Receptor-Associated Protein 31 & Hs. 522817 & -2.854 \\
\hline CRIP2 & Cysteine-Rich Protein 2 & Hs.534309 & -2.854 \\
\hline PRMT1 & Protein Arginine Methyltransferase 1 & Hs.20521 & -2.845 \\
\hline UBTF & Upstream Binding Transcription Factor, RNA Polymerase I & Hs.89781 & -2.837 \\
\hline PSMD13 & Proteasome (Prosome, Macropain) 26S Subunit, non-ATPase, 13 & Hs. 134688 & -2.831 \\
\hline KLHDC8B & Kelch Domain Containing 8B & Hs.13781 & -2.806 \\
\hline СCT7 & Chaperonin Containing Tcp1, Subunit 7 (ETA) & Hs.368149 & -2.804 \\
\hline LAMP1 & Lysosomal-Associated Membrane Protein 1 & Hs.494419 & -2.803 \\
\hline HSPA1A & Heat Shock 70 kDa Protein 1A & Hs. 520028 & -2.795 \\
\hline TEC & TEC Protein Tyrosine Kinase & Hs. 479670 & -2.78 \\
\hline UROD & Uroporphyrinogen Decarboxylase & Hs.78601 & -2.777 \\
\hline SEC13 & SEC13-Like 1 (S. Cerevisiae) & Hs.166924 & -2.768 \\
\hline ZNF496 & Zinc Finger Protein 496 & Hs.168677 & -2.757 \\
\hline FKBP4 & FK506 Binding Protein 4, $59 \mathrm{kDa}$ & Hs. 524183 & -2.732 \\
\hline RAB21 & RAB21, Member Ras Oncogene Family & Hs. 524590 & -2.727 \\
\hline FADS1 & Fatty Acid Desaturase 1 & Hs. 503546 & -2.724 \\
\hline DNAJB1 & Dnaj (Hsp40) Homolog, Subfamily B, Member 1 & Hs. 515210 & -2.71 \\
\hline ITPK1 & Inositol 1,3,4-Triphosphate 5/6 Kinase & Hs.30812 & -2.703 \\
\hline DDOST & Dolichyl-Diphosphooligosaccharide-Protein Glycosyltransferase & Hs. 523145 & -2.702 \\
\hline UBADC1 & Ubiquitin Associated Domain Containing 1 & Hs.9194 & -2.702 \\
\hline SLC29A1 & Solute Carrier Family 29 (Nucleoside Transporters), member 1 & Hs. 25450 & -2.694 \\
\hline KIAA0859 & KIAA0859 & Hs.647726 & -2.692 \\
\hline IGFBP6 & Insulin-Like Growth Factor Binding Protein 6 & Hs. 274313 & -2.691 \\
\hline PSMC3 & Proteasome (Prosome, Macropain) 26S Subunit, ATPase, 3 & Hs. 250758 & -2.682 \\
\hline KRT5 & Keratin 5 (Epidermolysis Bullosa Simplex, Dowling-Meara/Kobner/Weber-Cockayne Types) & Hs. 433845 & -2.682 \\
\hline EIF2S3 & Eukaryotic Translation Initiation Factor 2 , subunit $3 \gamma, 52 \mathrm{kDa}$ & Hs.539684 & -2.653 \\
\hline FOSL2 & FOS-Like Antigen 2 & Hs.220971 & -2.645 \\
\hline CLDN3 & Claudin 3 & Hs.647023 & -2.642 \\
\hline COPZ1 & Coatomer Protein Complex, Subunit $\zeta 1$ & Hs. 505652 & -2.636 \\
\hline GUK1 & Guanylate Kinase 1 & Hs.376933 & -2.609 \\
\hline AP2S1 & Adaptor-Related Protein Complex 2, $\sigma 1$ subunit & Hs.119591 & -2.585 \\
\hline SMARCE1 & Swi/Snf Related, Matrix Associated, Actin Dependent Regulator of Chromatin, Subfamily E, Member 1 & Hs.547509 & -2.584 \\
\hline FPGS & Folylpolyglutamate Synthase & Hs.335084 & -2.58 \\
\hline HLA-B & Major Histocompatibility Complex, Class I, B & Hs.77961 & -2.578 \\
\hline ID1 & Inhibitor Of DNA Binding 1, Dominant Negative Helix-Loop-Helix Protein & Hs.504609 & -2.576 \\
\hline
\end{tabular}


Table II. Continued.

\begin{tabular}{|c|c|c|c|}
\hline Gene symbol & Gene name & Unigene & Score $(d)$ \\
\hline MYBPH & Myosin Binding Protein $\mathrm{H}$ & Hs.927 & -2.546 \\
\hline GPAA1 & Glycosylphosphatidylinositol Anchor Attachment Protein 1 Homolog (Yeast) & Hs.627962 & -2.542 \\
\hline CLTB & Clathrin, Light Polypeptide (Lcb) & Hs. 484241 & -2.537 \\
\hline UBC & Ubiquitin $\mathrm{C}$ & Hs. 520348 & -2.53 \\
\hline DGCR6L & Digeorge Syndrome Critical Region Gene 6-Like & Hs.410965 & -2.526 \\
\hline SLC25A4 & Solute Carrier Family 25 (Mitochondrial Carrier; Adenine Nucleotide Translocator), member 4 & Hs.246506 & -2.505 \\
\hline KIAA0664 & KIAA0664 & Hs.22616 & -2.505 \\
\hline EIF3S4 & Eukaryotic Translation Initiation Factor 3, subunit $4 \delta, 44 \mathrm{kDa}$ & Hs.529059 & -2.503 \\
\hline FUS & Fusion [Involved IN T(12;16) in malignant liposarcoma] & Hs.513522 & -2.502 \\
\hline
\end{tabular}

Table III. Notable differentially expressed genes involved in biological processes strictly implicated in metastasis.

\begin{tabular}{|c|c|c|c|c|c|}
\hline Gene symbol & Gene name & Unigene & Biological process & Mean Log ratio & SE \\
\hline VCP & Valosin-containing protein & Hs. 529782 & $\begin{array}{l}\text { Cell communication/ } \\
\text { cell death }\end{array}$ & -1.6052 & 0.1691 \\
\hline DHX9 & DEAH (Asp-Glu-Ala-His) box polypeptide 9 & Hs.191518 & Cell death & -0.9132 & 0.1557 \\
\hline BIRC5 & Survivin (Baculoviral IAP Repeat-Containing 5) & Hs.645371 & Cell death & -0.5898 & 0.1485 \\
\hline ARPC1B & Actin Related Protein 2/3 Complex, Subunit 1B, $41 \mathrm{kDa}$ & Hs.489284 & Locomotion & -0.9834 & 0.1716 \\
\hline CTNNAL1 & $\alpha$-catulin [Catenin (cadherin-associated protein) $\alpha$-like 1] & Hs. 58488 & $\begin{array}{l}\text { Cell death/ } \\
\text { cell adhesion }\end{array}$ & 0.7292 & 0.3332 \\
\hline GADD45A & Growth arrest and DNA-damage-inducible, $\alpha$ & Hs.80409 & Cell growth arrest/cell death & 0.734 & 0.2455 \\
\hline AMFR & Autocrine Motility Factor Receptor & Hs. 295137 & $\begin{array}{l}\text { Cell communication/ } \\
\text { locomotion }\end{array}$ & -0.686 & 0.2492 \\
\hline MCAM & Melanoma Cell Adhesion Molecule & Hs.599039 & Cell adhesion & -1.0358 & 0.1748 \\
\hline
\end{tabular}

\section{Results}

The gene expression profiles of both L/B/K ALP- and CD99transfected clones were compared to those of the U-2/OS osteosarcoma cell line. Filtering and normalization of raw microarray data were performed using GP3. A total of 2506 cDNAs with GP3 quality-passed values were present in $100 \%$ of the arrays and were included in the final analysis by the SAM program. Four hundred and eighty sequences showed significantly different levels of expression in both L/B/K ALPand CD99-transfected osteosarcoma clones, compared to U-2 OS. Only genes that were up-regulated or down-regulated in at least $85 \%$ of the arrays and showing a highly significant change of expression (score of $>2.5$ or $<-2.5$ ) were considered (Table II). Of these genes, 75 were up-regulated whereas 178 were down-regulated in transfected osteosarcoma clones. We then assigned the different expressed genes to non-mutually exclusive functional categories regarding biological processes, using FatiGO. The selected genes covered a broad range of functional activities, including regulation of cellular growth, signal transduction, transport, cell death, cell differentiation, cell adhesion, and cell motility. Among all genes selected, great relevance was attached to the genes belonging to two functional categories, namely cell growth arrest/cell death and cell motility, since these are intimately involved in tumor progression and invasiveness (Table III). In particular, we identified several differentially expressed genes involved in the NF- $\mathrm{kB}$ cell survival pathway, a signaling pathway directly implicated in cancer cell survival and apoptosis, including the gene encoding Valosin-containing protein (VCP), DEAH (Asp-Glu-Ala-His) box polypeptide 9, (DHX9), Survivin (BIRC5) and Growth arrest and DNA-damage-inducible, $\alpha$ (GADD45 $\alpha$ ). GADD $45 \alpha$, which belongs to a family that encodes three nuclear proteins related with growth arrest and inducible by DNA damage proteins $(16,17)$, is up-regulated in both the transfected osteosarcoma cell lines, showing lack of metastatic ability. Since it is known that NF-кB-mediated repression of GADD $45 \alpha$ is sufficient for survival of various cancer cell types (18), it is conceivable that the up-regulation of GADD $45 \alpha$, may be dependent on inhibition of the NF- $\mathrm{kB}$ 


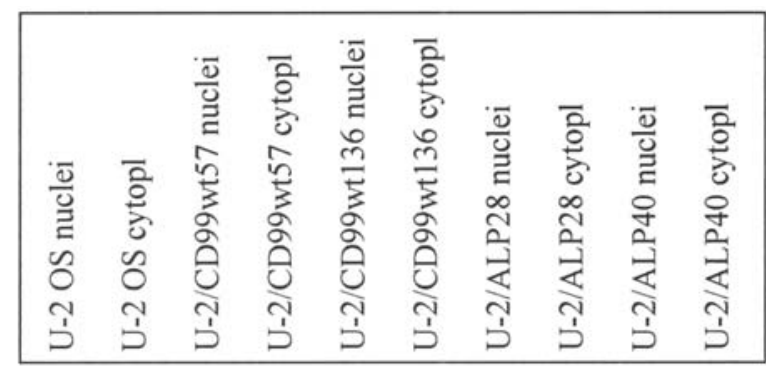

A
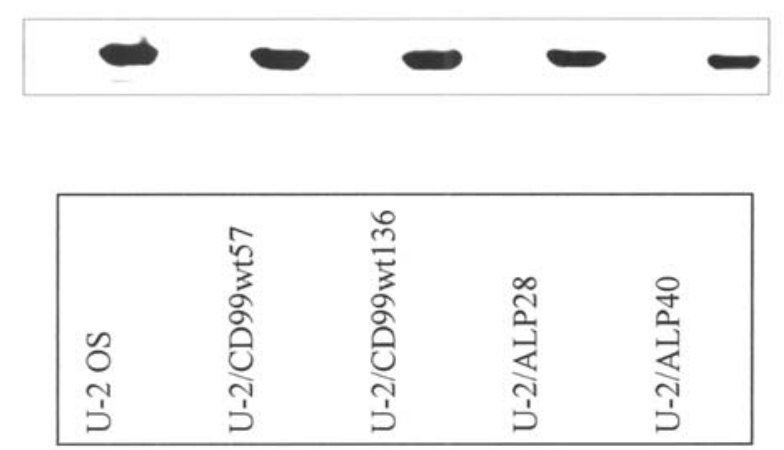

B

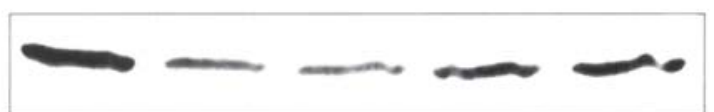

\section{U-2 OS}

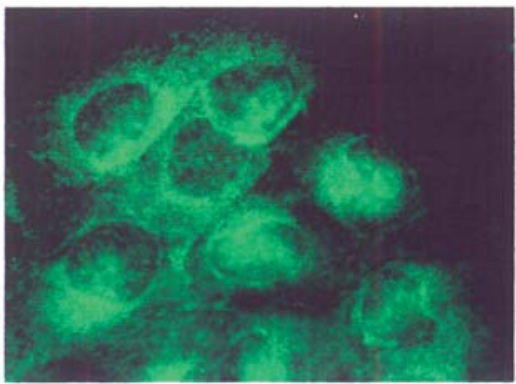

U-2/CD99 wt136

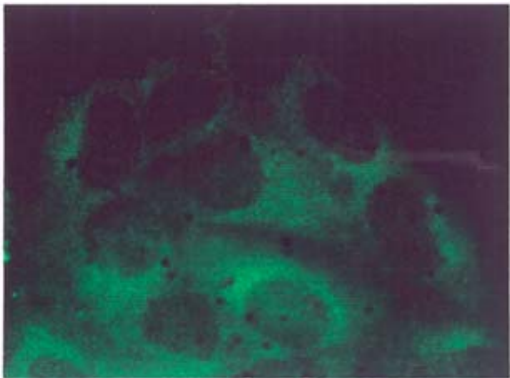

C

Figure 1. Protein nuclear fraction was extracted and GAPDH staining used to exclude cytoplasmic contamination. As expected GAPDH was evident only in the cytoplasmic but not in the nuclear fraction lysates (A). NF- $\mathrm{kB}$ expression was observed in the nuclear fractions of U-2 OS parental cells and transfectants. A lower level of NF-кB expression was observed in the less malignant variants both by Western blotting (B) and by immunofluorescence in adherent cells (C). Digital images were taken in identical conditions, at the same time and using the same image analysis software (Quips-XL genetic workstation, Abbot Visys).

signaling pathway. Indeed, we observed a decrease in the expression levels of NF- $\mathrm{KB}$ in the nucleus of U-2OS clones compared to parental cells (Fig. 1), which reflects a decreased activity of the nuclear factor. NF- $\mathrm{KB}$ is localized mainly in the cytoplasm in an inactive form bound to an inhibitory protein termed IkB (19-21). NF- $\mathrm{B}$ activation occurs via phosphorylation of $\mathrm{IkB}$, which is essential for the release of active NF- $\mathrm{BB}$ and its nuclear translocation, where it binds with specific DNA motifs in the promoter regions of target genes and activates their transcription. In keeping with a reduced NF- $\mathrm{KB}$ activity, in less malignant osteosarcoma clones we observed down-regulation of both VCP and DHX9, two activators of NK- $\mathrm{BB}$ pathways, and of Survivin, which is one of the downstream genes of the NF- $\mathrm{KB}$ pathway (Table III).
The microarray analysis suggests that inhibition of NF- $\mathrm{\kappa B}$ pathway signalling is an important mechanism to restore apoptosis/mitosis checkpoints. Quantitative PCR confirmed the significant decrease in the expression level of VCP and Survivin in all of the transfected clones (Fig. 2A). In accordance with this, we observed a decrease in the expression of cyclin D1 (Fig. 2B) and an increase in the apoptotic rate of U-2 OS transfected clones (Fig. 3A) that was particularly evident when cells were prevented from adhering (Fig. 3B). This is interesting since it is well known that non-transformed, anchorage-dependent cells undergo anoikis (i.e. detachmentinduced apoptosis) when deprived of contact with the extracellular matrix. In keeping with the lower level of malignancy, U-2/CD99 and U-2/ALP cell survival was severely reduced 
VCP
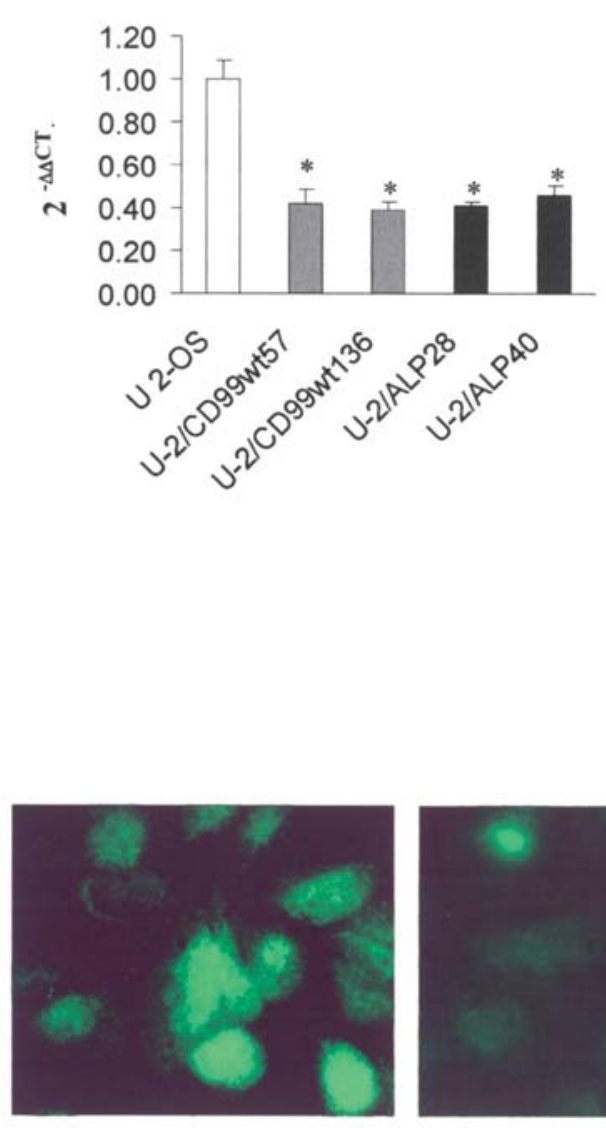

U-2 OS



U-2/CD99 57
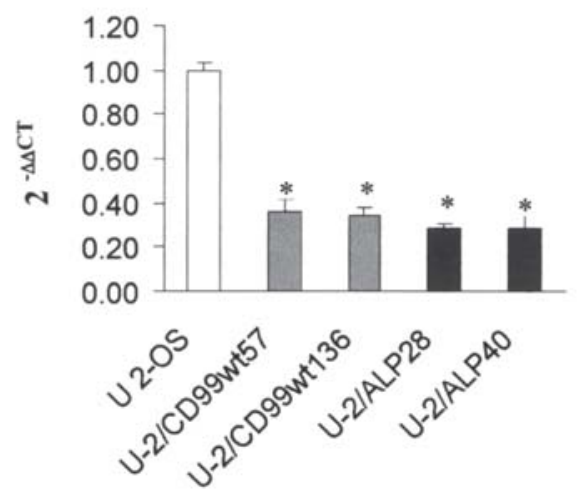

A

SURVIVIN

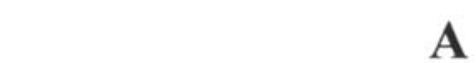

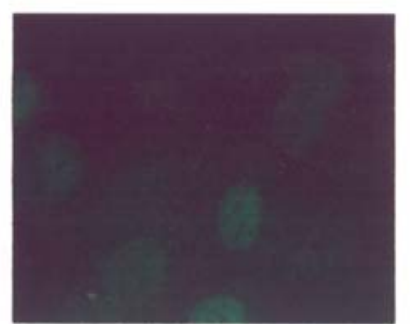

U-2/ALP28
B

Figure 2. (A) Relative expression of VCP and Survivin mRNA in U-2 OS parental and derived cells. The relative target gene mRNA expression of U-2 OS parental cells was used as a calibrator $\left(2^{-\triangle A C T}=1\right)$. Data are expressed as mean values \pm SE. (B) Immunostaining of cyclin D1 on adherent cells. U-2 OS transfectants expressed low levels of cyclin D1 in agreement with their lower malignant potential.

compared to parental cells when cells were cultured in a condition in which adherence of cells is prevented (15).

The decrease in Cyclin D1 expression may also be the consequence of the up-regulation of $\alpha$-catulin. $\alpha$-catulin is a member of the vinculin superfamily, whose mRNA expression appears to be differentially regulated following growth arrest of cells, suggesting that it may play a role in growth regulation (22). An antiproliferative role has been in fact demonstrated for $\alpha$-catulin based on attenuation of cyclin D1 transcription through inhibition of Ras-mediated signals to the cyclin D1 promoter (23). Thus its overexpression in U-2 OS transfected clones, also confirmed by real-time PCR data (Fig. 4A), is in line with the reduction of cyclin D1 expression and the lower level of malignancy of transfected clones. In addition, $\alpha$-catulin can associate with Rho pathway signaling in vivo, serving to localize Rho mediators in a multimolecular signaling complex linked to the cytoskeleton $(23,24)$. Acting as a cytoskeletal linker protein, up-regulation of $\alpha$-catulin in U-2 OS transfected clones may be associated with the higher level of actin cytoskeleton organization observed in these cells (Fig. 4B), negatively regulating actin disassembly and focal adhesion dynamics that characterize a motile phenotype. Indeed, U-2/
CD99 and U-2/ALP cells overexpressing $\alpha$-catulin exhibit features of strong adhesion, as characterized by abundant actin-stress fibers and focal adhesions (Fig. 4B), a pattern which has long been associated with cell differentiation and a stationary phenotype. Therefore, besides its antiproliferative role through decrease in cyclin D1 expression, $\alpha$-catulin may functionally participate in the suppression of transfected U-2OS cell motility (Fig. 5A). From a molecular point of view, the dynamic assembly and disassembly of actin filaments and the formation of larger scale filament structures, crucial aspects of actin's function, are under scrupulous control by $>100$ actin-binding proteins. The actin-related protein-2/3 (ARP2/3) complex was the first to be identified of an important set of actin regulators that initiate formation of new actin filaments (25). Although the precise mechanisms of the ARP $2 / 3$ complex are still poorly defined, these molecules are involved in the dynamic actin disassembly during cell migration. In our transfected osteosarcoma cell lines there was a down-regulation of the ARPC1B gene (Fig. 5B), which encodes p41, a subunit of the human Arp2/3 protein complex. Therefore underexpression of ARPC1B may contribute to inhibiting disruption of actin-containing stress fibers. 

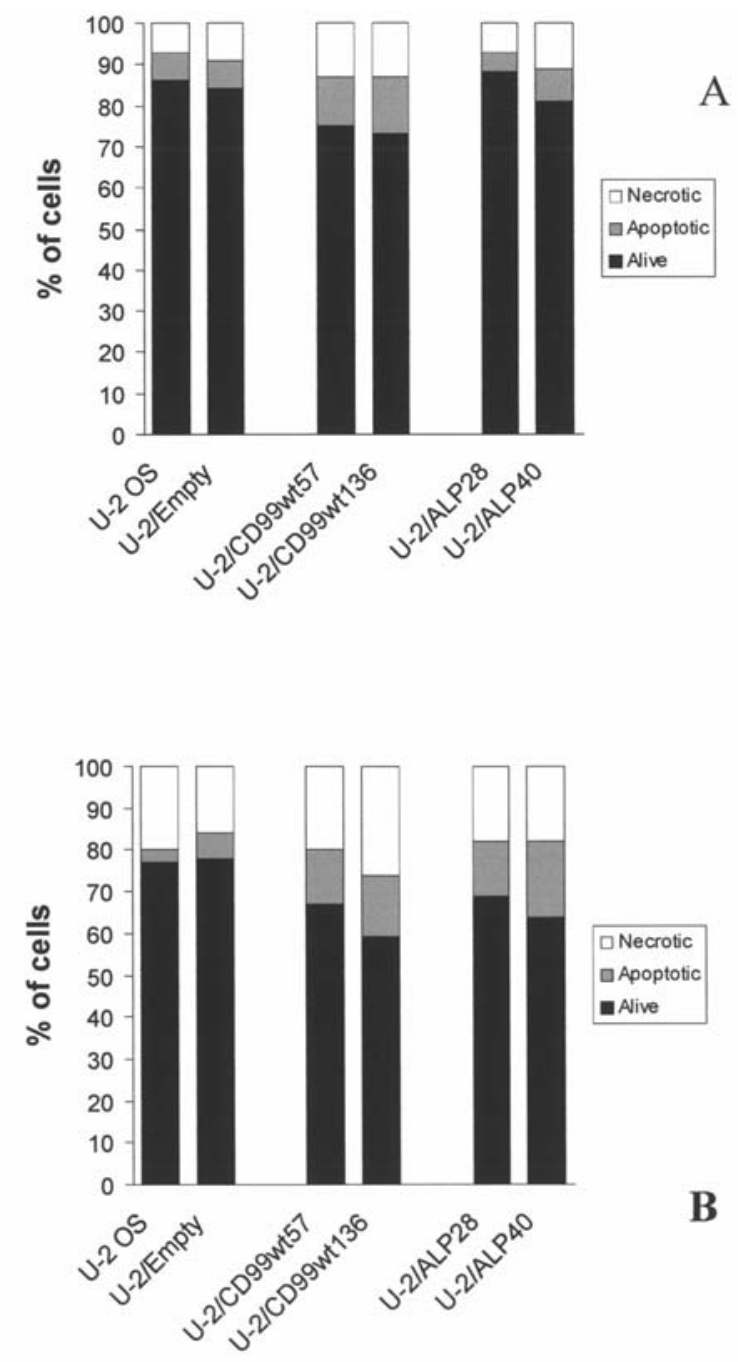

Figure 3. Cytofluorometric analysis of apoptotic U-2 OS cells and derivates by annexin- $\mathrm{V}$ and propidium iodide after $48 \mathrm{~h}$ in standard, monolayer, culture conditions (A) or on polyHEMA-coated dishes (B). Cells $(250,000)$ were seeded on untreated or polyHEMA-coated dishes in IMDM 10\% FBS and stained for annexin- $\mathrm{V}$ after $48 \mathrm{~h}$.

\section{Discussion}

The dissemination of osteosarcoma cells from the primary tumor to the lung is the most frequent cause of death among patients with osteosarcoma. In this study, with a view to identifying genes implicated in the spread of osteosarcoma, we employed osteosarcoma cell lines showing a reduction in metastatic ability as a result of L/B/K ALP-transfection and (likewise) CD99-transfection. Our data show that the reversal of the malignant phenotype observed in both differently transfected clones, may be due mainly to the modified expression of a set of genes related to growth arrest and apoptosis.

Recent studies have demonstrated that the forced expression of both CD99 and L/B/K ALP in U-2 OS osteosarcoma cell lines leads to an identical behavior by the differently transfected cancer cells, that is the abrogation of their invasiveness and metastatic ability $(4,5)$. By comparing the gene expression profiles of transfected clones showing a lack of metastatic ability with those of non-transfected osteosarcoma cell lines showing contrasting characteristics, we were able to identify
253 genes that were up-regulated or down-regulated in at least $85 \%$ of the arrays to a highly significant level. These genes are particular intriguing because, being regulated in a similar manner in the majority of transfected clones, they delineate a common transcriptional profile of the metastatic phenotype. These genes can be ascribed to a broad range of functional categories including regulation of cellular growth, signal transduction, transport, cell death, cell differentiation, cell adhesion, and cell motility. Two of the most modulated categories, apart from those related to metabolism, are known to be particularly involved in tumor progression and invasiveness, namely cell growth arrest/cell death and cell motility. Although the molecular mechanisms of metastasis are poorly understood, the resistance to apoptosis seems to be not only one of the required selective advantages that a cell has to acquire in order to form a tumor, but also a crucial process in regulating metastasis. In fact, the induction of programmed cell death is important for the development of the primary tumor because it limits the time available for the accumulation of tumorigenic alterations. However a number of recent experimental observations indicate that crucial apoptotic modulators such as NF- $\mathrm{B}$, BAX, BCL2, DAPK and survivin are deregulated in metastatic cancer cells $(26,27)$, providing support for the hypothesis that cancer cell survival and programmed cell death escape represent an advantage in metastatic behavior.

In our study we have pointed to regulation of the NF-kB cell survival pathway as a major molecular determinant of the metastasis process in osteosarcoma. In particular, we identified several differentially expressed genes involved in the NF- $\kappa$ B cell survival pathway, including GADD $45 \alpha$, VCP, DHX9 and survivin.

GADD $45 \alpha$ is up-regulated in both transfected osteosarcoma cell lines showing a lack of metastatic ability. The GADD45 gene family encodes nuclear proteins (GADD45 $\alpha, \beta, \gamma)$ that interact with various cell-cycle-related proteins $(16,17)$. It has been demonstrated that NF- $\mathrm{BB}$-mediated repression of GADD $45 \alpha$ is essential for various cancer cell types to escape programmed cell death (28). It is conceivable that the reversal of the malignant phenotype observed in our transfected osteosarcoma cell lines could equally be due in part to the up-regulation of GADD45 $\alpha$, which acts as a tumor suppressor gene.

VCP inhibits apoptosis via degradation of NF- $\mathrm{NB}$ inhibitor $(29,30)$. It has been ascertained that VCP gene expression is associated with the metastatic ability of many human tumors such as hepatocellular carcinoma (31), gastric carcinoma (32), pancreatic ductal adenocarcinoma (33) and murine osteosarcoma cell lines (30). Again, DHX9 is involved as a transcriptional co-activator in NF- $\mathrm{KB}$-mediated gene expression and its depletion reduces the NF- $\kappa \mathrm{B}$-dependent transactivation (34). In the present study both VCP and DHX9 are downregulated in U-2 OS transfected osteosarcoma cell lines showing a lack of metastatic ability. In addition, survivin, a member of the inhibitor of apoptosis protein (IAP) family, is likewise down-regulated in our transfected osteosarcoma cell lines. Survivin is one of the downstream genes of the NF- $\mathrm{KB}$ pathway (35) and is overexpressed in human cancer cells (36). Furthermore it acts as a regulator of mitosis in the G2-M checkpoint representing an important interface between 


\section{CTNNAL1}

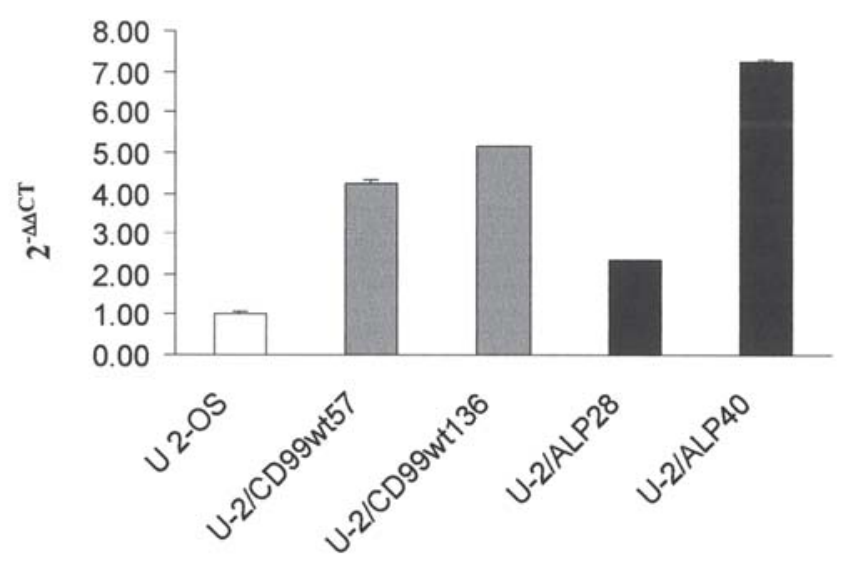

A

\section{U-2 OS}

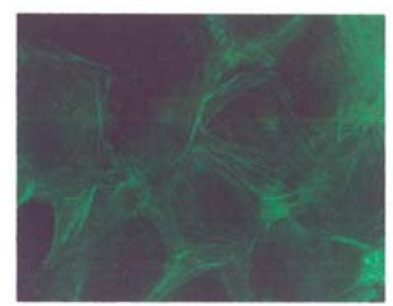

U-2/CD99wt57

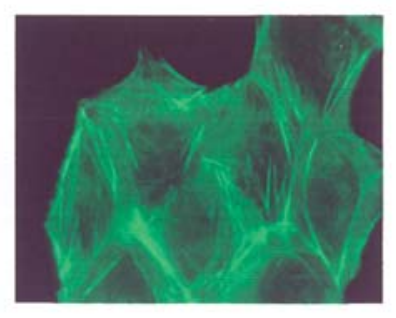

U-2/ALP28

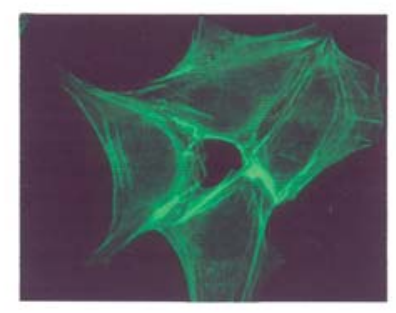

\section{B}

Figure 4. (A) Relative expression of CTNNAL1 mRNA in U-2 OS parental and derived cells. The relative target gene mRNA expression of U-2 OS parental cells was used as a calibrator $\left(2^{-\Delta \Delta C}=1\right)$. Data are expressed as mean values \pm SE. (B) Staining of actin filaments in U-2 OS cells. Cells transfected with CD99 or ALP show a higher level of actin expression and organization in keeping with a less migrating phenotype. Digital images were taken in identical conditions, at the same time and using the same image analysis software (Quips-XL genetic workstation, Abbott Visys).

cell-cycle progression and control of apoptosis (37). Survivin overexpression in cancer may obliterate this apoptotic checkpoint and allow the aberrant progression of transformed cells towards mitosis. The decrease in survivin, VCP, and DHX9 expression suggests that the observed lack of the malignant phenotype in transfected cell lines could be due to the restoration of apoptotic pathways, and especially sensitivity to anoikis, which was indeed observed in the clones with reduced malignancy when cells were experimentally prevented from adhering.

Interestingly, Mehlen and Puisieux (38) have convincingly reviewed the role of apoptosis as a multistep barrier that modulates the metastasis efficiency at three crucial levels: i) cell death, by anoikis and amorphosis, after the detachment of primary tumor cells from the extracellular matrix and neighboring cells; ii) the death of solitary cells in circulation through tumor immune surveillance or destruction by mechanical stresses; and iii) cell death during the phase of micrometastasis formation in a secondary organ. In line with the view that anoikis and amorphosis are crucial mechanisms during the metastatic process, the overexpression of $\alpha$-catulin in our transfected osteosarcoma cell lines is particularly intriguing. $\alpha$-catulin is a member of the vinculin superfamily, which includes proteins acting as mediators of cell-extracellular matrix adhesion, and seems to be one of the genes related to anoikis-sensitivity of tumor cells (39). $\alpha$-catulin has an antiproliferative role based on Ras-mediated inhibition of cyclin D1 promoter and is also involved in the regulation of actin polymerization, through its modulation of Rho signaling and interaction with $\beta$-catenin (23). Thus, $\alpha$-catulin up-regulation may explain the decrease in both cell growth and migration observed in U-2 OS transfected clones. Acting as a cytoskeletal linker protein, $\alpha$-catulin may participate, together with the Arp 2/3 complex, in regulation of the dynamic assembly and disassembly of actin filaments and in the formation of larger scale filament structures. $\alpha$-catulin may favor actin polymerization and strong cell adhesion, whereas the Arp 2/3 complex is known to regulate $\beta$-actin polymerization at the leading edge and hence cell protrusion, and is thus functionally connected with a motile phenotype (40). In confirmation of this pattern, in our transfected osteosarcoma cell lines showing reduced invasive ability there proves to be an up-regulation 

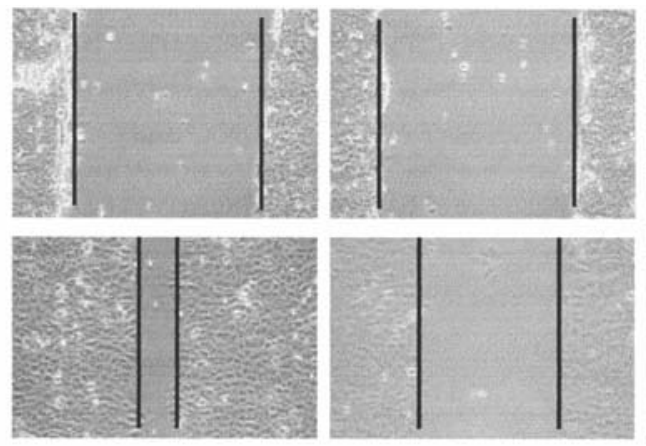

Time 0 h

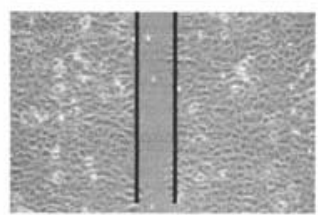

U-2/CD99wt57

osteosarcoma. Of note, all these genes are functionally related with the NF-кB signaling pathway that appeared to be inhibited in the less malignant osteosarcoma cells, in keeping with a previous study showing that the inhibition of constitutively active NF- $\mathrm{kB}$ leads to reversion of malignancy in osteosarcoma (42). Hence, sustained inhibition of NF- $\mathrm{KB}$ may be a rational strategy for effective management of this disease.

\section{Acknowledgements}

This study was supported by the European Projects EuroBonet (Katia Scotlandi). This work is dedicated to Paolo Carinci, Full Professor of Histology and Embriology at the University of Bologna, who strongly supported this research. Professor Carinci died in July 2007, leaving us the memory of his love for science and life.

\section{References}

1. Sporn MB: The war on cancer. Lancet 347: 1377-1381, 1996.

2. Dahlin DC: Bone Tumors: General Aspects and Data on 8,542 Cases. 4th edition. Springfield, IL, 1986.

3. Campanacci M: Bone and Soft Tissue Tumors. 2nd edition. Springer-Verlag, New York, 1999.

4. Manara MC, Baldini N, Serra M, et al: Reversal of malignant phenotype in human osteosarcoma cells transduced with the alkaline phosphatase gene. Bone 26: 215-220, 2000.

5. Manara MC, Bernard G, Lollini PL, et al: CD99 acts as an oncosuppressor in osteosarcoma. Mol Biol Cell 7: 1910-1921, 2006.

6. Banting GS, Pym B, Darling SM and Goodfellow PN: The MIC2 gene product: epitope mapping and structural prediction analysis define an integral membrane protein. Mol Immunol 26: 181-188, 1989.

7. Levy R, Dilley J, Fox RI and Wamk R: A human thymusleukemia antigen defined by hybridoma monoclonal antibodies. Proc Natl Acad Sci USA 76: 6552-6556, 1979.

8. Bernard G, Breittmayer JP, de Matteis M, Trampont P, Hofman P, Senik A and Bernard A: Apoptosis of immature thymocytes mediated by E2/CD99. J Immunol 158: 2543-2550, 1997.

9. Bernard G, Raimondi V, Alberti I, Pourtein M, Widjenes J, Ticchioni M and Bernard A: CD99 (E2) up-regulates alpha4beta1dependent $\mathrm{T}$ cell adhesion to inflamed vascular endothelium under flow conditions. Eur J Immunol 30: 3061-3065, 2000.

10. Pettersen RD, Bernard G, Olafsen MK, Pourtein M and Lie SO: CD99 signals caspase-independent T cell death. J Immunol 16: 4931-4942, 2001.

11. Alberti I, Bernard G, Rouquette-Jazdanian AK, Pelassy C, Pourtein M, Aussel C and Bernard A: CD99 isoforms expression dictates T cell functional outcomes. FASEB J 16: 1946-1948, 2002.

12. Bertaux K, Broux O, Chauveau C, Jeanfils J and Devedjian JC: Identification of CBFA1-regulated genes on SaOs-2 cells. J Bone Miner Metab 23: 114-122, 2005.

13. Fielden MR, Halgren RG, Dere E and Zacharewski TR: GP3: GenePix post-processing program for automated analysis of raw microarray data. Bioinformatics 18: 771-773, 2002.

14. Tusher VG, Tibshirani R and Chu G: Significance analysis of microarrays applied to the ionizing radiation response. Proc Natl Acad Sci USA 98: 5116-5121, 2001

15. Folkman J and Moscona A: Role of cell shape in growth control. Nature 273: 345-349, 1978

16. Hall PA, Kearsey JM, Coates PJ, Norman DG, Warbrick E and Cox LS: Characterisation of the interaction between PCNA and Gadd45. Oncogene 10: 2427-2433, 1995.

17. Chen IT, Akamatsu M, Smith ML, et al: Characterization of p21Cip1/Waf1 peptide domains required for cyclin E/Cdk2 and PCNA interaction. Oncogene 12: 595-607, 1996.

18. Zerbini LF, Wang Y, Czibere A, et al: NF-kappa B-mediated repression of growth arrest- and DNA-damage-inducible proteins 45alpha and gamma is essential for cancer cell survival. Proc Natl Acad Sci USA 101: 13618-13623, 2004.

19. Siebenlist U, Franzoso G and Brown K: Structure, regulation and function of NF-kappaB. Annu Rev Cell Biol 10: 405-455, 1994. 
20. Shao R, Hu MC, Zhou BP, Lin SY, Chiao PJ, von Lindern RH, Spohn B and Hung MC: E1A sensitizes cells to tumor necrosis factor-induced apoptosis through inhibition of IkappaB kinases and nuclear factor kappaB activities. J Biol Chem 274: 21495-21498, 1999.

21. Simeonidis S, Stauber D, Chen G, Hendrickson WA and Thanos D: Mechanisms by which IkappaB proteins control NF-kappaB activity. Proc Natl Acad Sci USA 96: 49-54, 1999.

22. Zhang J, Nelson M, Wang L, et al: Identification and chromosomal localization of CTNNAL1, a novel protein homologous to alpha-catenin. Genomics 54: 149-154, 1998.

23. Merdek KD, Nguyen NT and Toksoz D: Distinct activities of the a-catenin family, $\alpha$-catulin and $\alpha$-catenin, on B-cateninmediated signaling. Mol Cell Biol 24: 2410-2422, 2004.

24. Park B, Nguyen NT, Dutt P, et al: Association of Rho guanine nucleotide exchange factor with alpha-catenin-related protein, alpha-catulin/CTNNAL1, supports serum response factor activation. J Biol Chem 277: 45361-45370, 2002.

25. Deeks M and Hussey PJ: Arp2/3 and SCAR: plants move to the fore. Nat Rev Mol Cell Biol 6: 954-964, 2005.

26. Inbal B, Cohen O, Polak-Charcon S, Kopolovic J, Vadai E, Eisenbach L and Kimchi A: DAP kinase links the control of apoptosis to metastasis. Nature 390: 180-184, 1997.

27. Um JH, Kwon JK, Kang CD, et al: Relationship between antiapoptotic molecules and metastatic potency and the involvement of DNA-dependent protein kinase in the chemosensitization of metastatic human cancer cells by epidermal growth factor receptor blockade. J Pharmacol Exp Ther 311: 1062-1070, 2004.

28. Zerbini LF and Libermann TA: Life and death in cancer. GADD45 alpha and gamma are critical regulators of NF-kappaB mediated escape from programmed cell death. Cell Cycle 4: 18-20, 2005.

29. Dai RM, Chen E, Longo DL, Gorbea CM and Li CC: Involvement of valosin-containing protein, an ATPase co-purified with IkappaBalpha and $26 \mathrm{~S}$ proteasome, in ubiquitin-proteasomemediated degradation of IkappaBalpha. J Biol Chem 273: 3562-3573, 1998.

30. Asai T, Tomita Y, Nakatsuka S, Hoshida Y, Myoui A, Yoshikawa $\mathrm{H}$ and Aozasa K: VCP (p97) regulates NFkappaB signaling pathway, which is important for metastasis of osteosarcoma cell-line. Jpn J Cancer Res 93: 296-304, 2002.
31. Yamamoto S, Tomita Y, Nakamori S, et al: Elevated expression of valosin-containing protein (p97) in hepatocellular carcinoma is correlated with increased incidence of tumor recurrence. J Clin Oncol 21: 447-452, 2003.

32. Yamamoto S, Tomita Y, Hoshida Y, et al: Expression level of valosin-containing protein is strongly associated with progression and prognosis of gastric carcinoma. J Clin Oncol 21: 2537-2544, 2003

33. Hardy RG, Meltzer SJ and Jankowski JA: ABC of colorectal cancer. Molecular basis for risk factors. BMJ 321: 886-889, 2000.

34. Tetsuka T, Uranishi $\mathrm{H}$, Sanda T, Asamitsu K, Yang JP, Wong-Staal $\mathrm{F}$ and Okamoto T: RNA helicase A interacts with nuclear factor kappaB p65 and functions as a transcriptional coactivator. Eur J Biochem 271: 3741-3751, 2004.

35. Chen X, Kandasamy K and Srivastava RK: Differential roles of RelA (p65) and c-Rel subunits of nuclear factor kappa B in tumor necrosis factor-related apoptosis inducing ligand signaling. Cancer Res 63: 1059-1066, 2003.

36. Span PN, Sweep FC, Wiegerinck ET, Tjan-Heijnen VC, Manders P, Beex LV and de Kok JB: Survivin is an independent prognostic marker for risk stratification of breast cancer patients. Clin Chem 50: 1986-1993, 2004.

37. Li F, Ambrosini G, Chu EY, Plescia J, Tognin S, Marchisio PC and Altieri DC: Control of apoptosis and mitotic spindle checkpoint by survivin. Nature 396: 580-584, 1998.

38. Mehlen P and Puisieux A: Metastasis: a question of life or death. Nat Rev Cancer 6: 449-458, 2006.

39. Kupferman ME, Patel V, Sriuranpong V, et al: Molecular analysis of anoikis resistance in oral cavity squamous cell carcinoma. Oral Oncol 43: 440-454, 2006.

40. Wang W, Goswami S, Lapidus K, et al: Identification and testing of a gene expression signature of invasive carcinoma cells within primary mammary tumors. Cancer Res: 64: 8585-8594, 2004.

41. Gournier H, Goley ED, Niederstrasser H, Trinh T and Welch MD: Reconstitution of human Arp2/3 complex reveals critical roles of individual subunits in complex structure and activity. Mol Cell 8: 1041-1052, 2001.

42. Andela VB, Sheu TJ, Puzas EJ, Schwarz EM, O'Keefe RJ and Rosier RN: Malignant reversion of a human osteosarcoma cell line, Saos-2, by inhibition of NFkappaB. Biochem Biophys Res Commun 297: 237-241, 2002. 